\title{
Effects of "Starch:Water" Ratio on Gelatinization of pinhão Starch from Nine Germplasm Collections, Measured by Differential Scanning Calorimetry
}

\author{
Camila D. Bet ${ }^{\mathrm{a}}$, Rossane C. B. Godoy ${ }^{\mathrm{b}}$, Layse P. Cordoba $^{\mathrm{a}}$, Ivo M. Demiate ${ }^{\mathrm{a}}$, \\ LUIZ G. LACERDA ${ }^{\mathrm{a}}$, AND EGON SCHNitZleR ${ }^{\mathrm{a}^{*}}$ \\ a State University of Ponta Grossa, Av. Carlos Cavalcanti, 4748, 84030-900, Ponta Grossa, PR, Brazil \\ b Embrapa Forestry-Brazilian Agricultural Research Corporation - Estrada da Ribeira, Km 111 - P.O. Box 319, \\ 83411-000 - Colombo, PR, Brazil \\ ${ }^{*}$ Corresponding author \\ egons@uepg.br \\ TEL: +55 042 3220-3093
}

Received: 21 December 2017; Published online: 18 October 2019

\begin{abstract}
Native starch was extracted from nine germplasm collections of Araucaria angustifolia seeds in aqueous medium and they were characterized by Pasting Properties (RVA), X-ray Powder Diffractometry (XRD) and Scanning Electron Microscopy (SEM). The gelatinization process of each sample was evaluated at different ratios of starch:water by Differential Scanning Calorimetry (DSC). A slight displacement in the gelatinization curves was observed for the pinhão starches prepared with different amounts of water. With an increase in water content, most of the samples presented a decrease in the peak, the conclusion temperatures, and the range of gelatinization temperatures, while the enthalpy did not follow a standard behavior. A displacement or a narrowing of the gelatinization temperature range occurred with increasing water content. Pinhão starch showed pasting temperature in the range of $60-67{ }^{\circ} \mathrm{C}$ and there were differences in the pasting properties and degree of relative crystallinity between the analyzed samples. The C-type diffraction pattern was found for all the samples and the morphology of starch granules was similar, with oval and round shapes. Therefore, different characteristics were found among starches from nine germplasm collections, encouraging the protection of the biological diversity of selected species, aiming at future applications.
\end{abstract}

Keywords: pinhão starch; Gelatinization; Pasting properties; Germplasm; Thermal analysis

\section{Introduction}

Starch, among the carbohydrates, is one of the most abundant renewable sources, widely used for industrial purposes due to its physicochemical properties and low cost. The main economic sources of starches are plants, in which this biopolymer occurs in various sites (cereal grains, seeds, roots and tubers, stems, etc.) as tiny white granules. They may present an oval, spherical, round, polygonal or lenticular shape, with a diameter range of $<1$ up to $100 \mu \mathrm{m}$. Starch granules are composed mainly of two glucose polymers called amylose (with a linear form consisting of up to 3000 glucose units; interconnected primarily by $\alpha-1,4$ glycosidic linkages) and amylopectin (a large branched polymer with $\alpha-1,4$ linkages that serve as a backbone and $\alpha-1,6$ bridges at the branch points) (Bicudo et al., 2009; de Conto, Vicente Plata-Oviedo, Steel, \& Chang, 2011; Pinto, Moomand, et al., 
2015; Pinto et al., 2012; Thys, Aires, Marczak, \& Noreña, 2013).

"Pinh ão" is the name of the seeds from "Paraná pine", a tree that belongs to the Araucariaceae family (Araucaria angustifolia syn. Araucaria brasiliensis). This tree grows in forests of Brazil (South Region), Paraguay, Argentina, and Chile; however, it is threatened with extinction due to excessive extraction of its wood. The pinhão seeds are consumed by humans (mainly during the winter) after cooking in water and later peeling and also used as flour in regional cuisine. The main component of pinhão seeds is starch (68-72\%, dry basis), but protein (around 3\%), lipid (around 1\%), soluble sugars (around 2.4\%), as well as dietary fibers, phenolic compounds and minerals such as copper and magnesium are also found (Cordenunsi et al., 2004; Daudt, Kuelkamp-Guerreiro, Cladera-Olivera, Silveira Thys, \& Ferreira Marczak, 2014; Ribeiro et al., 2014).

Germplasm collections are sources of genetic variability for plant breeding. These techniques are available and necessary with the aim to protect the biological diversity of selected species, mainly those that are at risk for extinction. Thus, EMBRAPA Forests created a germplasm bank with 224 different types of conifer Araucaria, in the city of Colombo, PR, Brazil (BelloPerez et al., 2006; Oliveira Gomes da Costa et al., 2013; Villalobos, Ferreira, \& Mora, 1991).

Gelatinization is a process that occurs when the starch-water slurry is heated, and the starch granules swell. The energy required for molecular order disruption of starch granules differs according to their botanical origin. With the DSC technique, this molecular disorder is often observed as an endothermic phenomenon (Kohyama, Matsuki, Yasui, \& Sasaki, 2004; Malucelli et al., 2015). As starch is used in the food industry to confer some functional properties, this investigation was carried out to characterize the starches from nine different sources of pinhão seeds and evaluate the gelatinization process at different ratios of starch:water.

\section{Materials and Methods}

\subsection{Materials}

The genetic resources of the pinhão seeds were collected in the germplasm bank (Embrapa Forestry-Colombo-PR-Brazil) and all the seeds were collected in June (2016), at the same maturation stage.

\section{$2.2 \quad$ Starch extraction}

The starch extraction was carried out according to Bello-Perez et al. (2006) with the following modifications proposed by Oliveira Gomes da Costa et al. (2013): the main coat (hard) of seeds was removed as well as the second coat (a thin layer) adhered to the surface. Isolated seeds were milled, and an equal mass of distilled water was added. The suspension was mechanically stirred for $10 \mathrm{~min}$, sieved (200 mesh or $0.075 \mathrm{~mm}$ ) and centrifuged (5000 rpm for $10 \mathrm{~min}$ ). Obtained starch was carefully dried in an oven with forced air circulation at $40{ }^{\circ} \mathrm{C}$ for $24 \mathrm{~h}$. Finally, the purified starch was kept in a desiccator over anhydrous calcium chloride up to constant mass.

\subsection{Differential scanning calorimetry (DSC)}

The DSC curves were obtained using a DSCQ200 model (TA-Instr. Co., USA). Initially the instrument was calibrated with $99.99 \%$ standard indium, m.p. $=156.6^{\circ} \mathrm{C}, \Delta \mathrm{H}=28.56 \mathrm{~J} \mathrm{~g}^{-1}$. Each sample was prepared, in triplicate, as follows: $2.0 \mathrm{mg}$ of starch sample and $8.0 \mu \mathrm{L}$ of distilled water were added to an aluminum crucible (sample with starch:water ratio 1:4). Afterward, the crucible was sealed and held at rest for 60 min (samples A1 to A9) to perform DSC analysis. The same procedure was adopted for other samples with starch:water ratios of 1:5 (samples B1 to B9) and 1:6 (samples C1 to C9). The conditions of the instrument for each analysis were: heating rate of $10{ }^{\circ} \mathrm{C} \mathrm{min}-1$ from $30{ }^{\circ} \mathrm{C}$ to 100 ${ }^{o} \mathrm{C}$ under air flow of $50 \mathrm{~mL} \mathrm{~min}{ }^{-1}$ and an empty aluminum crucible was used as reference. The temperature onset $\left(\mathrm{T}_{o}\right)$, peak temperature $\left(\mathrm{T}_{p}\right)$, endset or conclusion temperature $\left(\mathrm{T}_{c}\right)$, as well as 
Different water content in the gelatinization of the pinhão starch $\mid 15$

gelatinization enthalpy $\left(\Delta \mathrm{H}_{\text {gel }}\right)$ were calculated (Malucelli et al., 2015).

\subsection{Pasting properties (RVA)}

The pasting profiles of the studied starches were obtained in triplicate according to the literature (Hornung, de Oliveira, Lazzarotto, da Silveira Lazzarotto, \& Schnitzler, 2016) using the Rapid Visco Analyser (RVA-4, Newport Sci., Australia). Sample moisture was previously measured to prepare a suspension containing 8 $\%$ starch (dry basis), with the addition of water to make up the total mass of $28 \mathrm{~g}$ in the RVA canister.

The suspensions were subjected to a programmed heating and cooling cycle (STD-2, Thermocline for Windows), where they were continuously stirred at $160 \mathrm{rpm}$. The temperature was maintained at $50{ }^{\circ} \mathrm{C}$ for $2 \mathrm{~min}$, then heated to $95{ }^{\circ} \mathrm{C}$ at a rate of $6{ }^{\circ} \mathrm{C} \mathrm{min}^{-1}$ and held at this temperature for $5 \mathrm{~min}$. Finally, the mass was cooled to $50{ }^{\circ} \mathrm{C}$ at a rate of $6{ }^{\circ} \mathrm{C} \min ^{-1}$ and maintained for $2 \mathrm{~min}$.

\subsection{X-ray diffractograms (DRX)}

Each sample was analyzed in triplicate on a glass support and exposed to $\mathrm{CuK} \alpha$ radiation (wavelength $1.5418 \AA$ ), subjected to $40 \mathrm{kV}$ and current of $20 \mathrm{~mA}$ in the X-ray diffractometer (Ultima 4, Rigaku Co., Japan). The scattered radiation was detected in the angular range of $5-50^{\circ}(2 \Theta)$ with scanning speed of $8 \mathrm{~min}^{-1}$ and a step of $0.06^{\circ}$. The relative crystallinity was calculated in agreement with the method previously described (Zhang, Xie, Zhao, Liu, \& Gao, 2009).

\subsection{Morphological analysis (SEM)}

Scanning electron microscopy (SEM) was carried out with the instrument VEGA3 (TESCAN, Czech Rep.). The parameters of analysis were: $20 \mu \mathrm{m}$ in the reading scale, with a voltage of 20 $\mathrm{kV}$ in the electron beam, tungsten filament and retro mirrored electron detector. The instrument is based on electrons passing through the previously prepared sample. Initially, the sample was attached to a carbon tape and prepared by a metallization process with gold and palladium plasma. The mean diameter of the granules was calculated with the aid of AZtec software (Bet, Cordoba, Ribeiro, \& Schnitzler, 2016).

\subsection{Statistical analysis}

After assuming normality of the data and verifying the homoscedasticity of the variances (p>0.05) by Levene's test, differences between the means were verified by analysis of variance (ANOVA) and compared by Duncan's test $(\mathrm{p}<0.05)$. The software programs used were ACTION $^{T M}$ and SASM-Agri ${ }^{T M} 8.2$.

\section{Results and discussion}

Heating of starch in the presence of water leads to an irreversible transformation known as gelatinization, which is characteristic of the botanical origin and molecular composition of each starch. This phenomenon is an endothermic process that results in the disruption of molecular order (double helical and crystalline structures) within the starch granules with the creation of a molecular dispersion called a "paste" or "gel" (Klein et al., 2013; Kohyama et al., 2004). Among the different analytical methods, differential scanning calorimetry (DSC) has been preferred for measuring starch gelatinization (Wani et al., 2012). Figure 1 shows the DSC curves and it is possible to observe a slight displacement in the thermal event for the samples containing different proportions of water.

Differences between the pinhão starches from nine germplasm accessions in the DSC results can be visualized in Table 1. It was observed that, by comparing all the samples, the highest onset and peak temperature values were exhibited by samples 1,5 and 7 ( $\mathrm{T}_{o}$ between $60.3-62.5^{\circ} \mathrm{C}$; $\mathrm{Tp}$ between $\left.66.2-67.5^{\circ} \mathrm{C}\right)$. Lower values of gelatinization temperature $\left(\mathrm{T}_{o}\right.$ between $51.0-53.7^{\circ} \mathrm{C} ; \mathrm{T}_{p}$ between $58.1-60.6^{\circ} \mathrm{C}$ ) were observed for samples 4 and 9 ; and $\mathrm{T}_{p}$ around $61.4-62.4^{\circ} \mathrm{C}$ for samples 2 and 3 .

Other values of $\mathrm{T}_{p}$ from gelatinization of pinh $\tilde{a} o$ starch reported in the literature were: 66.65 (Pinto et al., 2012), 62.44 (Ribeiro et al., 2014), 55.55 (Daudt et al., 2014), 63.4 (Bello-Perez et 
$16 \mid$ Bet et al.

Table 1: DSC, XRD and SEM results of nine different species of pinhão starch, where A corresponds to the samples prepared in a ratio of 1:4 (starch:water); $\mathrm{B}$ in a ratio of 1:5 and $\mathrm{C}$ in a ratio of $1: 6$ for DSC analysis

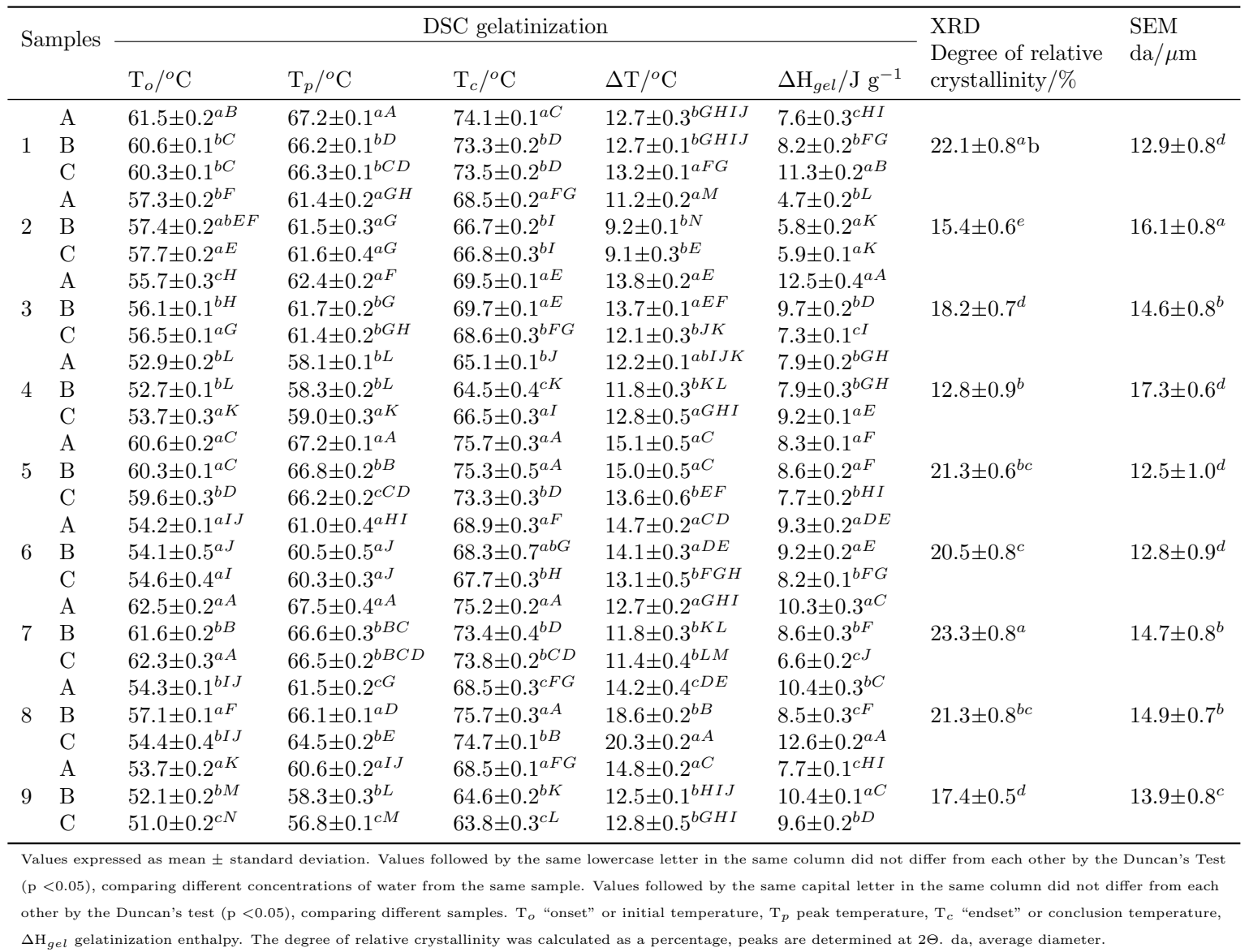

Table 2: VA results of pinhão starch from nine different germplasm collections (1-9)

\begin{tabular}{|c|c|c|c|c|c|c|}
\hline Samples & $\begin{array}{l}\text { Pasting } \\
\text { temperature } /{ }^{\circ} \mathrm{C}\end{array}$ & $\begin{array}{l}\text { Viscosity } \\
\text { peak/cP }\end{array}$ & $\begin{array}{l}\text { Peak } \\
\text { time/sec }\end{array}$ & Setback/cP & Breakdown/cP & $\begin{array}{l}\text { Final } \\
\text { viscosity } / \mathrm{cP}\end{array}$ \\
\hline 1 & $64.8 \pm 0.5^{b}$ & $3087.0 \pm 85.1^{a}$ & $335.4 \pm 5.0^{f}$ & $1309.5 \pm 40.0^{b c}$ & $1798.0 \pm 42.5^{a}$ & $2606.8 \pm 70.2^{a}$ \\
\hline 2 & $60.8 \pm 0.6^{e}$ & $1933.8 \pm 45.0^{g}$ & $445.7 \pm 7.8^{a}$ & $1345.4 \pm 31.7^{a b}$ & $813.2 \pm 45.5^{f}$ & $2467.7 \pm 69.6^{b}$ \\
\hline 3 & $62.4 \pm 0.5^{d}$ & $2960.3 \pm 62.6^{b}$ & $363.7 \pm 6.5^{c}$ & $1360.8 \pm 65.8^{a b}$ & $1673.6 \pm 60.7^{b}$ & $2664.5 \pm 40.6^{a}$ \\
\hline 4 & $60.2 \pm 0.4^{e}$ & $2703.5 \pm 55.1^{c d}$ & $319.6 \pm 5.5^{g}$ & $1190.1 \pm 70.0^{d e}$ & $1493.1 \pm 40.4^{c}$ & $2386.4 \pm 44.2^{b c}$ \\
\hline 5 & $66.3 \pm 0.4^{a}$ & $2743.8 \pm 66.8^{c}$ & $357.6 \pm 2.1^{c d}$ & $1257.8 \pm 40.2^{c d}$ & $1437.5 \pm 60.1^{c d}$ & $2591.5 \pm 34.9^{a}$ \\
\hline 6 & $63.6 \pm 0.4^{c}$ & $2350.9 \pm 50.0^{f}$ & $350.3 \pm 6.5^{d e}$ & $1148.7 \pm 45.4^{e}$ & $1050.3 \pm 50.5^{e}$ & $2445.0 \pm 42.3^{b}$ \\
\hline 7 & $67.0 \pm 0.3^{a}$ & $2714.8 \pm 41.0^{c d}$ & $367.0 \pm 4.6^{c}$ & $1383.5 \pm 30.6^{a b}$ & $1406.8 \pm 40.4^{c d}$ & $2694.8 \pm 75.0^{a}$ \\
\hline 8 & $64.3 \pm 0.5^{b}$ & $2556.8 \pm 50.3^{e}$ & $378.3 \pm 3.7^{b}$ & $1171.0 \pm 33.7^{e}$ & $1385.5 \pm 73.5^{d}$ & $2339.9 \pm 60.1^{c}$ \\
\hline 9 & $60.0 \pm 0.2^{e}$ & $2634.2 \pm 35.5^{d e}$ & $348.0 \pm 56.0^{e}$ & $1433.8 \pm 56.0^{a}$ & $1416.2 \pm 68.7^{c d}$ & $2654.8 \pm 49.2^{a}$ \\
\hline
\end{tabular}

IJFS | October 2019 | Volume 8 | pages 13-22 
Different water content in the gelatinization of the pinhão starch $\mid 17$
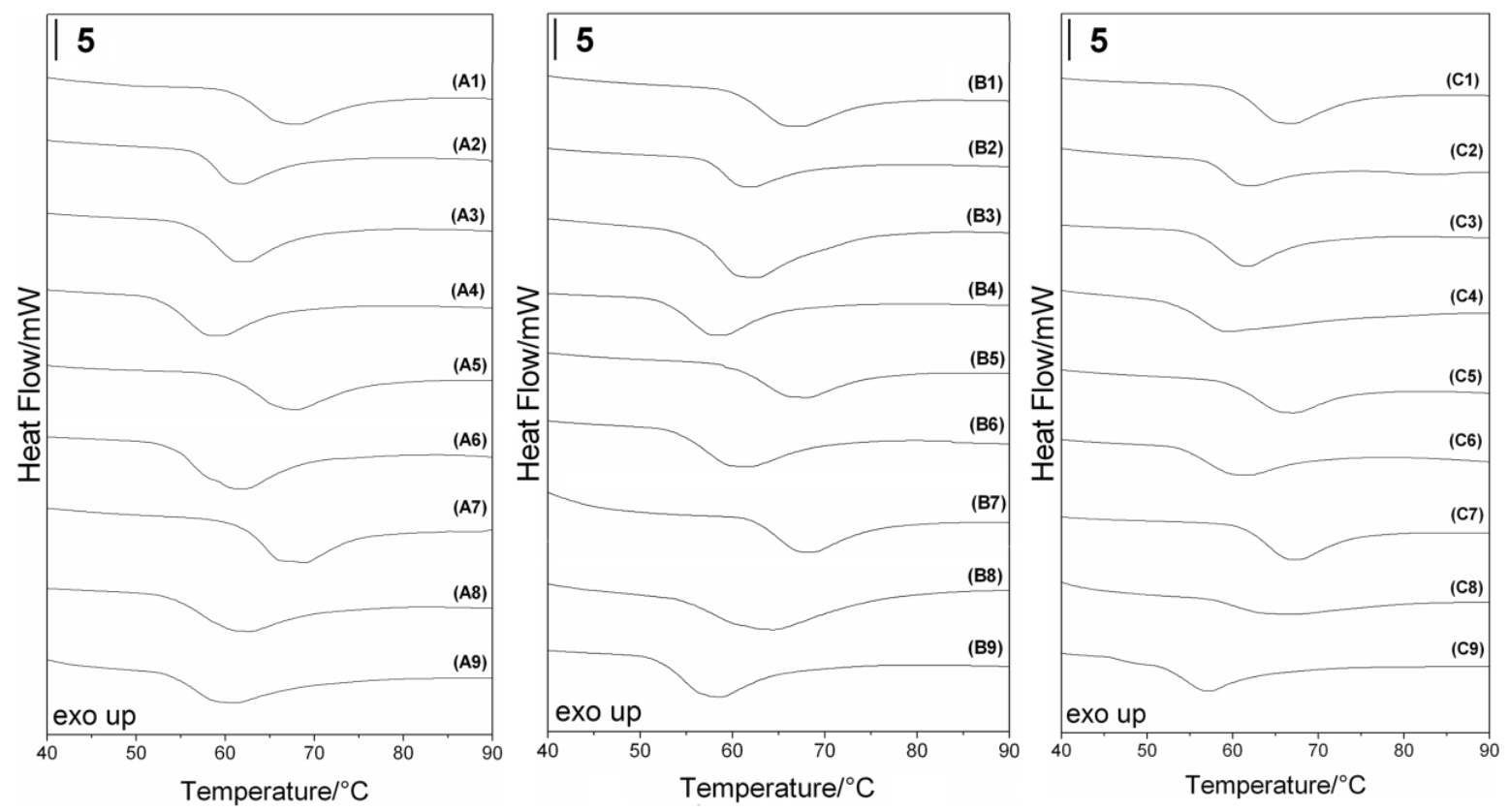

Figure 1: DSC gelatinization curves of different species of pinhão starch, where A1 to A9 correspond to the samples prepared in a ratio of 1:4 (starch:water); B1 to B9 in a ratio of 1:5 and $\mathrm{C} 1$ to $\mathrm{C} 9$ in a ratio of of 1:6

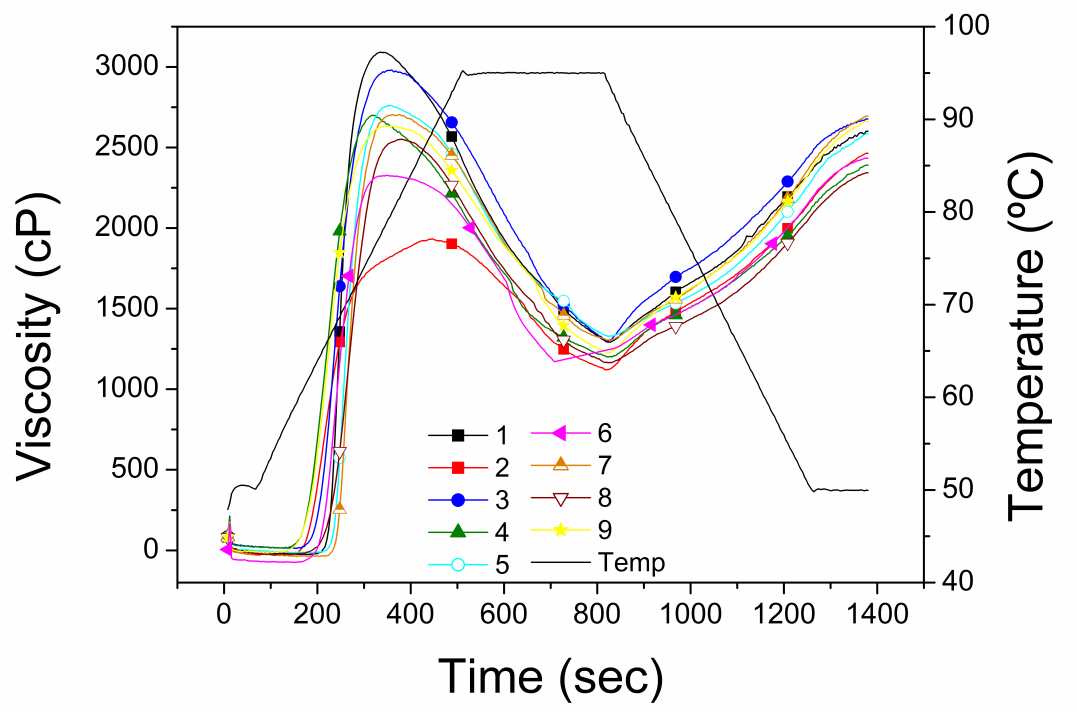

Figure 2: RVA curves of pinhão starch from nine different germplasm collections (1-9) 
al., 2006), 60.15 (Pinto, Vanier, Deon, et al., $2015)$ and $66.69^{\circ} \mathrm{C}$ (Klein et al., 2013), suggesting that these samples were acquired in respective local commerce (from different cities) in the southern region of Brazil.

Zortéa-Guidolin et al. (2017) found values of $\mathrm{T}_{p}$ between $58.3-64.5^{\circ} \mathrm{C}$ for pinhão starches from seven accessions of the same germplasm bank used in the present study.

Similar results for the transition temperatures were reported by Oliveira Gomes da Costa et al. (2013) for pinhão starch from four germplasm banks in Embrapa (Brazil), with a 1:4 ratio (starch:water). However, the gelatinization enthalpy was higher $(24.23,20.23,16.87$ and 10.40 $\mathrm{J} \mathrm{g}^{-1}$ ) than that found in this study, where samples 3A (1:4 starch:water ratio) and 8C (1:6 starch:water ratio) had the highest values (12.5 and $12.6 \mathrm{~J} \mathrm{~g}^{-1}$, respectively, yet with no significant difference by Duncan's Test, $\mathrm{p}<0.05)$ and sample $2 \mathrm{~A}$ had the lowest value $\left(4.7 \mathrm{~J} \mathrm{~g}^{-1}\right)$. Zortéa-Guidolin et al. (2017) also reported higher values of $\Delta \mathrm{H}_{\text {gel }}$, between 12.5 to $14.5 \mathrm{~J} \mathrm{~g}^{-1}$.

Considering the starch:water ratios $(1: 4,1: 5$ and 1:6), slight differences in the peak temperatures $\left(\mathrm{T}_{p}\right)$ were observed. For most of the samples (1, $3,5,7$ and 9 ), the increase in the water content led to decreased $\mathrm{T}_{p}$. In addition, a decrease in the transition temperature range was observed for samples 2, 3, 5, 6, 7 and 9, and an increase for samples 1,4 and 8. This was also observed for flour and starch of chestnuts in different water contents (Torres, Moreira, Chenlo, \& Morel, 2013).

It was suggested that this occurred due to the plasticising action of water over starch crystals, which assists in the conduction of energy, favoring a greater mobility of chains, and therefore, a lower temperature is necessary for this irreversible transition (Schirmer, Zeller, Krause, Jekle, \& Becker, 2014). The water content did not significantly affect $(\mathrm{p}<0.05)$ the onset and the peak temperatures for samples 2 and 6 . Only samples 4 and $8 \mathrm{~B}$ showed an increase in $\mathrm{T}_{p}$ value. The increase in the water content promoted a decrease in the conclusion temperature, suggesting a displacement or a narrowing of the gelatinization range.

The gelatinization enthalpy $\left(\Delta \mathrm{H}_{\text {gel }}\right)$ showed differences between each sample. Samples 1, 2 and
4 showed an increase in $\Delta \mathrm{H}_{\text {gel }}$ proportional to the starch:water ratio increase, as was observed for flour and starch of chestnut (Torres et al., 2013). Samples 3, 5, 6 and 7 showed a decrease and the others did not follow this behavior.

Some differences in DSC values for peak temperature $\left(\mathrm{T}_{p}\right)$ and gelatinization enthalpy $\left(\Delta \mathrm{H}_{\text {gel }}\right)$ of native pinhão starches among different authors can be attributed to differences among the samples (samples from market or selected from germplasm banks), different starch extraction processes (aqueous medium or chemical), instrument conditions (heating rate, starch:water ratio) and architecture of the crystalline region. In addition, the initial moisture as well as the way the water diffuses between the chains may be a determinant in the gelatinization of the starch (Hoover, 2001).

The pasting properties of each analyzed pinhão starch were performed and the RVA curves are shown in Figure 2.

Differences can be noted among the samples, and for better visualization the results are presented in Table 2. pinhão starch showed lower pasting temperature values, different from other unmodified starches such as corn (Malucelli et al., 2015), cassava (Hornung et al., 2016; Hornung, Granza, de Oliveira, Lazzarotto, \& Schnitzler, 2015), common vetch (Bet et al., 2016), avocado (Lacerda et al., 2015), European chestnut (Lopes et al., 2016), carioca bean (Granza et al., 2015) and potato (Leivas et al., 2013).

In this investigation, samples 7 and 5 showed the highest values of pasting temperature (67.0 and $66.3{ }^{\circ} \mathrm{C}$, respectively, without significant difference by Duncan's Test, $\mathrm{p}<0.05)$ and samples 2, 4 and 9 showed the lowest $(60.8 ; 60.2$ and $60.0{ }^{\circ} \mathrm{C}$, respectively, without significant difference by Duncan's Test, $\mathrm{p}<0.05)$. These data corroborate that observed in $\mathrm{T}_{o}$, determined by DSC, although the values by this analysis were lower, as observed by Park, Lbanez, Zhong, and Shoemaker (2007). DSC is a highly sensitive method, allowing the detection of temperatures at the beginning of the gelatinization process as a thermal response. On the other hand, the pasting temperature is related to the minimum cooking temperature of the starch, when the viscosity increases due to the maximum volume of swollen granules, which will already be disinte- 
grated due to the shear used in this analysis. Thus, these temperatures can be correlated, and a lower value is expected from the higher sensitivity analysis (DSC) (Noisuwan, Bronlund, Wilkinson, \& Hemar, 2008).

The highest viscosity of starch slurry was found for sample $1(3091.0 \mathrm{cP})$ and the lowest for sample $2(1931.5 \mathrm{cP})$, which also had the lowest enthalpy (DSC). The final viscosity of pinhão starch, which indicates the ability to form a viscous paste, was highest for samples $1,3,5,7$ and 9 (without significant differences by Duncan's Test, $\mathrm{p}<0.05$ ) and lowest for samples 2, 4 and 8. Zortéa-Guidolin et al. (2017) also observed high final viscosity from seven accessions of the same germplasm bank, but the values of the bonding properties were different from the present study.

The relative crystallinity of the studied pinhão starches was quantitatively calculated based on the relationship between the peaks and the total area of diffraction patterns, and values are shown in Table 1 . The lowest value was obtained for sample 2, which also showed the lowest enthalpy value of gelatinization. The highest relative crystallinity was exhibited by samples 1 and 7 (without significant differences by Duncan's Test, $\mathrm{p}<0.05)$. According to Hoover (2001), enthalpy may be correlated to the quantity and order of the double helices of amsylopectin, mainly to the distribution of short chains, that is to say, the molecular architecture of the starch. In another study with pinhão starch from four germplasm collections, authors found values between 25.43-28.43\% (Oliveira Gomes da Costa et al., 2013). In a recent study (Zortéa-Guidolin et al., 2017), authors described values of relative crystallinity of pinhão starch from seven germplasm collections and their results were between $26.37-30.46 \%$.

The X-ray diffractograms of native pinhão starch showed peaks at $15^{\circ}, 17^{\circ}$ and $23^{\circ}(2 \Theta)$, and another small peak at approximately $5.7^{\circ}$, typical of C-type structures, and as also observed by other authors (Daudt et al., 2014; Pinto et al., 2012; Zortéa-Guidolin et al., 2017).

Regarding SEM analysis, the morphology of all samples presented oval and round shapes as previously reported by Pinto, Moomand, et al. (2015) and Bello-Perez et al. (2006) and hemispherical or truncated ellipsoid shapes with smooth surfaces (Zortéa-Guidolin et al., 2017). In this investigation, the average diameter of the samples is shown in Table 1, with values between 12.8-16.1 $\mu \mathrm{m}$. In other studies, the average diameter of starches from pinhão was $22.9 \mu \mathrm{m}$ Pinto, Moomand, et al. (2015) and $13.98 \mu \mathrm{m}$ (Ribeiro et al., 2014). Other values of average diameter of pinhão starches from germplasm accessions reported in the literature were 12.41 to $16.21 \mu \mathrm{m}$ (Oliveira Gomes da Costa et al., 2013) and 12 $\mu \mathrm{m}$ (Zortéa-Guidolin et al., 2017).

\section{Conclusions}

The proposed study shows differences in gelatinization processes of pinhão starch from nine germplasm collections. When a starch suspension was prepared in a small amount of water, higher peak and conclusion temperatures and gelatinization temperature ranges were observed, since water is a limiting factor for gelatinization of the starch. It was not possible to relate the enthalpy to the water content.

New studies may be carried out, such as the determination of amylose/amylopectin ratio, which directly influences starch properties and may be different for species from the same botanical source. Differences in the pasting properties were identified between the samples. The X-ray diffraction pattern indicated that the starch was C-type, and an oval shape was observed for the starch granules. Since germplasm is related to genetic resource protection, further characteristics must be evaluated for its preservation and other rational uses.

\section{Acknowledgements}

The authors are grateful to CNPq-Brazil; proc $\mathrm{n}^{\circ}$ 307983/2014-5, Araucaria Foundation-PR-Brazil and CAPES-Brazil, for research support and scholarship.

\section{References}

Bello-Perez, L. A., Garcia-Suarez, F. J., MendezMontealvo, G., do Nascimento, J. R. O., Lajolo, F. M., \& Cordenunsi, B. R. (2006). 
Isolation and characterization of starch from seeds of araucaria brasiliensis: A novel starch for application in food industry. Starch-starke, 58(6), 283-291. doi:10.1002/ star.200500455

Bet, C. D., Cordoba, L. d. P., Ribeiro, L. S., \& Schnitzler, E. (2016). Common vetch (vicia sativa) as a new starch source: Its thermal, rheological and structural properties after acid hydrolysis. Food Biophysics, 11 (3), 275-282. doi:10.1007/s11483-0169439-2

Bicudo, S. C. W., Demiate, I. M., Bannach, G., Lacerda, L. G., Filho, M. A. S. C., Ionashiro, M., \& Schnitzler, E. (2009). Thermoanalytical study and characterization of native starches of paraná pine seeds (araucaria angustiofolia, bert o. ktze) and european chestnut seeds (castanea sativa, mill). Eclética Química, 34(1), 7 12. doi:10.1590/S0100-46702009000100001

Cordenunsi, B. R., De Menezes, E. W., Genovese, M. I., Colli, C., De Souza, A. G. A., \& Lajolo, F. M. (2004). Chemical composition and glycemic index of brazilian pine (araucaria angustifolia) seeds. Journal of Agricultural and Food Chemistry, 52(11), 34123416. doi:10.1021/jf0348141

Daudt, R. M., Kuelkamp-Guerreiro, I. C., Cladera-Olivera, F., Silveira Thys, R. C., \& Ferreira Marczak, L. D. (2014). Determination of properties of pinhao starch: Analysis of its applicability as pharmaceutical excipient. Industrial Crops and Products, 52, 420-429. doi:10.1016/j.indcrop.2013.10.052

de Conto, L. C., Vicente Plata-Oviedo, M. S., Steel, C. J., \& Chang, Y. K. (2011). Physico-chemical, morphological, and pasting properties of pine nut (araucaria angustifolia) starch oxidized with different levels of sodium hypochlorite. Starchstarke, 63(4), 198-208. doi:10.1002/star . 201000133

Granza, A. G., Travalini, A. P., Farias, F. O., Denck Colman, T. A., Schnitzler, E., \& Demiate, I. M. (2015). Effects of acetylation and acetylation-hydroxypropylation (dual-modification) on the properties of starch from carioca bean (phaseolus vulgaris 1.) Journal of Thermal Analysis and
Calorimetry, 119(1), 769-777. doi:10.1007/ s10973-014-4092-9

Hoover, R. (2001). Composition, molecular structure, and physicochemical properties of tuber and root starches: A review. Carbohydrate Polymers, 45(3), 253-267. doi:10. 1016/S0144-8617(00)00260-5

Hornung, P. S., de Oliveira, C. S., Lazzarotto, M., da Silveira Lazzarotto, S. R., \& Schnitzler, E. (2016). Investigation of the photooxidation of cassava starch granules. Journal of Thermal Analysis and Calorimetry, 123(3), 2129-2137. doi:10.1007/s10973015-4706-x

Hornung, P. S., Granza, A. G., de Oliveira, C. S., Lazzarotto, M., \& Schnitzler, E. (2015). Study of the effects of ultraviolet light and sodium hypochlorite solutions on properties of cassava starch granules. Food Biophysics, 10(3), 368-374. doi:10.1007/ s11483-015-9402-7

Klein, B., Pinto, V. Z., Vanier, N. L., Zavareze, E. d. R., Colussi, R., do Evangelho, J. A., ... Guerra Dias, A. R. (2013). Effect of single and dual heat-moisture treatments on properties of rice, cassava, and pinhao starches. Carbohydrate Polymers, 98(2), 1578-1584. doi:10.1016/j.carbpol.2013.07. 036

Kohyama, K., Matsuki, J., Yasui, T., \& Sasaki, T. (2004). A differential thermal analysis of the gelatinization and retrogradation of wheat starches with different amylopectin chain lengths. Carbohydrate Polymers, 58(1), 71-77. doi:10.1016/j.carbpol. 2004.06 .032

Lacerda, L. G., da Silva Carvalho Filho, M. A., Bauab, T., Demiate, I. M., Denck Colman, T. A., Pereira Andrade, M. M., \& Schnitzler, E. (2015). The effects of heat-moisture treatment on avocado starch granules thermoanalytical and structural analysis. Journal of Thermal Analysis and Calorimetry, 120(1), 387-393. doi:10.1007/s10973-0143987-9

Leivas, C. L., Oliveira Gomes da Costa, F. J., de Almeida, R. R., Sossela de Freitas, R. J., Stertz, S. C., \& Schnitzler, E. (2013). Structural, physico-chemical, thermal and pasting properties of potato (solanum 
Different water content in the gelatinization of the pinhão starch $\mid 21$

tuberosum 1.) flour. Journal of Thermal Analysis and Calorimetry, $111(3), 2211-$ 2216. doi:10.1007/s10973-012-2395-2

Lopes, B. D. M., Demiate, I. M., Ito, V. C., de Oliveira, C. S., da Silva Carvalho Filho, M. A., Schnitzler, E., \& Lacerda, L. G. (2016). Effects of partial in vitro digestion on properties of european chestnut (castanea sativa mill) flour. Thermochimica Acta, 640, 36-41. doi:10.1016/j.tca. 2016.07.012

Malucelli, L. C., Lacerda, L. G., Silva da Carvalho Filho, M. A., Rodriguez Fernandez, D. E., Demiate, I. M., Oliveira, C. S., \& Schnitzler, E. (2015). Porous waxy maize starch thermal, structural and viscographic properties of modified granules obtained by enzyme treatment. Journal of Thermal Analysis and Calorimetry, 120(1), 525532. doi:10.1007/s10973-015-4483-6

Noisuwan, A., Bronlund, J., Wilkinson, B., \& Hemar, Y. (2008). Effect of milk protein products on the rheological and thermal (dsc) properties of normal rice starch and waxy rice starch. Food Hydrocolloids, 22(1), 174-183. 8th International Hydrocolloids Conference, Norwegian Univ Sci \& Technol, Trondheim, NORWAY, JUN 1822, 2006. doi:10.1016/j.foodhyd.2007.01. 009

Oliveira Gomes da Costa, F. J., Leivas, C. L., Waszczynskyj, N., Bueno de Godoi, R. C., Helm, C. V., Denck Colman, T. A., \& Schnitzler, E. (2013). Characterisation of native starches of seeds of araucaria angustifolia from four germplasm collections. Thermochimica Acta, 565, 172-177. doi:10. 1016/j.tca.2013.04.030

Park, I.-M., Lbanez, A. M., Zhong, F., \& Shoemaker, C. F. (2007). Gelatinization and pasting properties of waxy and non-waxy rice starches. Starch-starke, 59(8), 388396. doi:10.1002/star.200600570

Pinto, V. Z., Moomand, K., Vanier, N. L., Colussi, R., Villanova, F. A., Zavareze, E. R., ... Dias, A. R. G. (2015). Molecular structure and granule morphology of native and heat-moisture-treated pinhao starch. International Journal of Food Science and Tech- nology, 50(2), 282-289. doi:10.1111/ijfs . 12608

Pinto, V. Z., Vanier, N. L., Deon, V. G., Moomand, K., Mello El Halal, S. L., Zavareze, E. d. R., ... Guerra Dias, A. R. (2015). Effects of single and dual physical modifications on pinhao starch. Food Chemistry, 187, 98-105. doi:10.1016/j . foodchem.2015.04.037

Pinto, V. Z., Vanier, N. L., Klein, B., Zavareze, E. d. R., Elias, M. C., Gutkoski, L. C., ... Guerra Dias, A. R. (2012). Physicochemical, crystallinity, pasting and thermal properties of heat-moisture-treated pinhao starch. Starch-starke, 64 (11), 855-863. doi:10.1002/star.201200040

Ribeiro, L. S., Cordoba, L. d. P., Denck Colman, T. A., de Oliveira, C. S., Pereira Andrade, M. M., \& Schnitzler, E. (2014). Influence of some sugars on the thermal, rheological and morphological properties of "pinhao" starch. Journal of Thermal Analysis and Calorimetry, 117(2), 935-942. doi:10. 1007/s10973-014-3778-3

Schirmer, M., Zeller, J., Krause, D., Jekle, M., \& Becker, T. (2014). In situ monitoring of starch gelatinization with limited water content using confocal laser scanning microscopy. European Food Research and Technology, 239(2), 247-257. doi:10.1007/ s00217-014-2213-0

Thys, R. C. S., Aires, A. G., Marczak, L. D. F., \& Noreña, C. P. Z. (2013). The effect of acid hydrolysis on the technological functional properties of pinhão (araucaria brasiliensis). Ciência e Tecnologia de Alimentos, 33(1), 89-94. doi:10.1590/S010120612013000500014

Torres, M. D., Moreira, R., Chenlo, F., \& Morel, M. H. (2013). Effect of water and guar gum content on thermal properties of chestnut flour and its starch. Food Hydrocolloids, 33(2), 192-198. doi:10 . 1016/j . foodhyd . 2013.03.004

Villalobos, V. M., Ferreira, P., \& Mora, A. (1991). The use of biotechnology in the conservation of tropical germplasm. Biotechnology Advances, 9(2), 197-215. doi:10 . 1016/0734-9750(91)90004-F 
Wani, A. A., Singh, P., Shah, M. A., SchweiggertWeisz, U., Gul, K., \& Wani, I. A. (2012). Rice starch diversity: Effects on structural, morphological, thermal, and physicochemical properties-a review. Comprehensive Reviews in Food Science and Food Safety, 11(5), 417-436. doi:10.1111/j.1541-4337. 2012.00193.x

Zhang, L., Xie, W., Zhao, X., Liu, Y., \& Gao, W. (2009). Study on the morphology, crystalline structure and thermal properties of yellow ginger starch acetates with different degrees of substitution. Thermochimica Acta, 495(1-2), 57-62. doi:10.1016/j. tca.2009.05.019

Zortéa-Guidolin, M. E. B., Demiate, I. M., de Godoy, R. C. B., de Paula Scheer, A., Grewell, D., \& Jane, J.-l. (2017). Structural and functional characterization of starches from brazilian pine seeds (araucaria angustifolia). Food Hydrocolloids, 63, 19-26. doi:10.1016/j.foodhyd.2016.08.022 